\title{
Evaluating the Success of a Science Academic Development Programme at a Research-intensive University
}

\author{
Johann Engelbrecht ${ }^{*}$, Ansie Harding and Marietjie Potgieter \\ University of Pretoria, Pretoria, South Africa \\ ${ }^{*}$ Corresponding author: Johann Engelbrecht, University of Pretoria, Pretoria, South Africa. \\ Email: johann.engelbrecht@up.ac.za
}

\begin{abstract}
Academic development (AD) programmes for students not complying with the entrance requirements of mainstream programmes in science have been running at a number of universities in South Africa. In this study we contribute to the debate on criteria for the success of AD programmes, specifically in the context of research-intensive universities in South Africa. We identify five quantitative criteria for evaluating such a programme: retention, completion rate, migration to other faculties, comparison with other institutions and enrolment in graduate studies. Most of these criteria are relatively common in evaluating similar programmes whereas the extent of migration to other faculties is particular to this study. We illustrate the use of these criteria evaluating the BSc Four Year Programme at the University of Pretoria based on the group of students who registered for the programme in 2008. We found that around $15 \%$ of this group had completed their studies in the minimum time while the eventual completion rate of students getting degrees is expected to be in the order of $50 \%$. The attrition rate across the four year science degree programme was high $(43 \%)$, but the majority of students who terminated their studies did so during the first year. Of those still enrolled in their fourth year a high percentage of students remained in science-related programmes $(79 \%)$. The fact that more than half of first graduates had enrolled for postgraduate programmes in 2012 is a criterion for success that is especially important for a research-intensive university.
\end{abstract}

Keywords: Academic development; retention; success; science programmes; access; attrition; evaluation criteria

\section{Introduction}

The numbers of school learners qualifying for science and engineering degree programmes in South Africa have been relatively low and have even been dropping for the past few years. Reports (Campbell \& Prew, 2014; Department of Basic Education, 2014) indicate a 17\% decline in the number of candidates who wrote mathematics between 2009 and 2013 (from about 290,400 to $241,400)$. At the same time, the number of candidates writing mathematics literacy rose sharply to $58 \%$ of the 2013 cohort. Likewise, the number of candidates who wrote physical science also fell by $17 \%$ over the same period (from about 220,900 to 184,300). Critically, as the number of learners selecting to do mathematics is dropping, the overall number who are achieving an NSC pass with more than $40 \%$ in mathematics has been falling over the same period to $17 \%$ of the class of 2013 (Campbell \& Prew, 2014; Department of Basic Education, 2014).

This unfortunate situation is a consequence of the challenge that the secondary school system still faces, namely to increase the pool of prospective science students despite enormous disadvantages in relation to adequate school systems with quality teaching environments. The problem of the implications of dealing with diversity at different levels was discussed in a study by Scott, Yeld and 
Hendry (2007) in which they suggested that interventions should address systemic issues (such as educational structures) as well as regular teaching-and-learning approaches.

Extended, foundation and augmented programmes, collectively referred to as access programmes or academic development (AD) programmes, are currently presented in various forms at universities in South Africa (Council on Higher Education, 2013). In 2006, the government introduced earmarked funding for foundation provision, which made it possible for most universities to offer extended curricula, particularly in science and engineering. It is required that all foundation courses should be credit-bearing and form part of formal extended degree programmes (Case, Marshall \& Grayson, 2013). These programmes aim to offer talented, educationally disadvantaged students, who do not qualify to be admitted to mainstream university programmes, the opportunity to access university programmes through an initially reduced pace and intensified teaching strategies. In this study we evaluate the initial success of the extended BSc Four Year Programme presented at the University of Pretoria, using five quantitative criteria that can be used for evaluating similar programmes.

These AD programmes are manpower intensive and require the sustained input of a specific kind of lecturer who is a specialist teacher as well as a disciplinary expert. However, since international ranking instruments for universities focus strongly on research performance rather than on providing access to science programmes to a diverse student community, this causes a dilemma at researchintensive universities. It becomes quite difficult to find the right balance between these two almost conflicting objectives of being research productive on the one hand and providing specialised teaching and effective student support on the other.

\section{Background}

\section{Historical Background}

The history of $A D$ provision in South Africa is generally accepted to have followed three phases characterised by distinct practices and discourses (Boughey, 2007). During the early 1980s an academic support model was practised in response to the perceived needs of the, then, small numbers of black students entering historically white, liberal universities (Boughey, 2010). This was followed by academic development from 1990 onwards, which centred on the development of curricula and teaching methodologies to meet the needs of growing numbers of black students entering tertiary education. The third phase, institutional development, emerged at the turn of the century and was prompted by the demands that globalisation has placed on tertiary institutions in South Africa. During the past three decades $A D$ has undergone several theoretical and ideological shifts as a result of changes in policy and in the discourse regarding its purpose and function (e.g. Boughey, 2007). The shifts that have occurred and are still in process move from a focus on equity to a focus on efficiency, from addressing student deficit to creating a responsive tertiary environment (Case et al., 2013). Considerable knowledge and expertise in AD provision have been acquired in South Africa over three decades. This includes expertise on the nature of disadvantage and under-preparedness, the design of effective student development initiatives, selection and placement, and institutional transformation (Boughey, 2010). At the heart of this enterprise is the need for a qualified workforce for the economic development of South Africa and the quest for equity, equality and social justice (Boughey, 2007; Kioko, 2010).

All of the 23 tertiary institutions in South Africa are currently offering some form of AD for science degrees and/or diploma programmes as reflected by their websites. These offerings can be categorised as extended, foundation or augmented programmes in accord with Department of Higher Education and Training (DHET) requirements for its overall design. In extended programmes the foundation modules and modules from the first academic year of a BSc degree are integrated and distributed in a coherent manner over two years and the extra time is used for academic support and skills development. Foundation programmes typically consist of a one-year curriculum of preparatory science and academic literacy modules after which a student enters mainstream BSc. In the augmented model first-year modules are spread over two years with concurrent support in the form of extra tutorials and/or practicals. Extended degree programmes are a more recent model for $A D$ designed to address some of the limitations of the earlier models of foundation and augmentation (Council on 
Table 1: Overview of AD programmes in the sciences at traditional and comprehensive universities in South Africa, status quo for 2014

\begin{tabular}{|c|c|c|c|}
\hline & Extended model & Foundation model & $\begin{array}{l}\text { Augmented } \\
\text { model }\end{array}$ \\
\hline $\begin{array}{l}\text { Traditional } \\
\text { universities }\end{array}$ & $\begin{array}{l}\text { Cape Town, Pretoria, Witwatersrand, } \\
\text { North-West, Western Cape, Limpopo, } \\
\text { Fort Hare }\end{array}$ & $\begin{array}{l}\text { Stellenbosch, Free State, } \\
\text { KwaZulu-Natal, Rhodes }\end{array}$ & KwaZulu-Natal \\
\hline $\begin{array}{l}\text { Comprehensive } \\
\text { universities }\end{array}$ & $\begin{array}{l}\text { Johannesburg, Nelson Mandela } \\
\text { Metropolitan, UNISA, Walter Sisulu }\end{array}$ & Venda, Zululand & Zululand \\
\hline
\end{tabular}

Higher Education, 2013). Table 1 provides a summary of the current provision of AD programmes at traditional and comprehensive universities in South Africa. Not reflected in Table 1 is the fact that all universities of technology also offer extended programmes for a selection of their national diplomas and some of their BTech programmes. The programme that is reported on in this article is an extended degree programme.

While AD was flourishing in the early 1990s, a decade later its capacity to contribute to the transformation and development of South African higher education was being questioned by some researchers (Boughey, 2007). A number of studies have more recently been conducted on students' access and success that focused either only on AD programmes or holistically on undergraduate education, including $A D$ provision. This includes large-scale commissioned reports by the Council on Higher Education (2013) and Inyathelo (2014), an analysis of foundational provision in South Africa by Dhunpath and Vithal (2013) and reports of success stories in foundation/extended programmes published by the Foundation Special Interest Group of HELTASA (Higher Education Learning and Teaching Association of South Africa) (HELTASA, 2010). This paper makes a contribution to the debate on effectiveness and success of academic development programmes in South Africa as reflected in these reports.

\section{Entrance}

Students enter AD programmes on grounds of performance in selection tests (for some programmes). Selection of students into AD programmes demands careful consideration. Not only are the costs of selecting the wrong students high but admitting students who do not have adequate probability of succeeding in higher education, is generally regarded as unethical. Selection can be seen as a contract to teach at the student's level. Every selected student must have a reasonable expectation of success after admission to a study programme. Although there have been instances of institutionally designed or other selection tests for aptitude (Van der Flier, Thys \& Zaaiman, 2003), the majority of tertiary institutions have recently opted to make use of the National Benchmark Tests, designed to be used countrywide (Grayson, 2010).

The Centre for Science Access at the University of Kwazulu-Natal (UKZN) operates an unusual entrance policy. Alternative access routes to tertiary science studies are offered to educationally disadvantaged students who do not meet formal faculty entrance requirements. These students enter one of the two foundation streams, either the Extended Curriculum Programme (BSc 4-Foundation; for those who achieve matriculation endorsement) or the Science Foundation Programme (for those whose matriculation is not endorsed). Although they are registered differently, students in both these streams follow the same curriculum, and attend the same classes. Together these streams are referred to as the 'Foundation Programme' (Kirby \& Dempster, 2011).

\section{Success}

Universities use a number of criteria to evaluate general undergraduate programmes, mainly focusing on the achievement of pre-set learning objectives; quality of teaching staff members; quality of graduate output; student success; employment placement after completion of the programme; student personal growth; and articulation of the programme with other programmes within the university and at other 
leading institutions (Inyathelo, 2014; SUNY, 2012; White, 2011). These criteria apply to general undergraduate programmes and are not necessarily directly transferable to AD programmes.

Detailed completion rates are documented as one measure of success for AD programmes (HELTASA, 2010). This term indicates the proportion of a given intake or cohort of students that graduates (also referred to as cohort graduation rate). The term 'completion rate' is preferred to avoid possible confusion with different interpretations of the term 'graduation rate'. The University of the Witwatersrand (WITS) reports that over the period 1992-2005 the BSc four-year degree programme showed a completion rate of just under $50 \%$, outperforming the WITS BSc three-year programme that showed a completion rate of $42 \%$ over the same period. At the UKZN, over the period 1996$2002,63 \%$ of AD programme students either graduated or were on course for graduation, comparable with the $65 \%$ for regular programme students (HELTASA, 2010). Lower figures of $43 \%$ and $31 \%$ were reported (Council on Higher Education, 2013) for the Augmented and Foundation programme intakes at UKZN, respectively, for the period 2005-2008. As yet another measure of success of AD programmes, the Tshwane University of Technology reports a disappointingly high attrition rate during and directly following the first foundational year, but an impressive success rate after that, on par with regular programme students.

At WITS, students moving to other faculties and subsequent graduation is also seen as success (HELTASA, 2010). Such students use their achievement in the AD programme for access to faculties and courses that they would otherwise not have qualified for. The definitive measure of success is how many students enroll and complete postgraduate studies. For the period $1992-2005,17 \%$ of students in the WITS College of Science transferred to other programmes, and $38 \%$ of these eventually graduated (HELTASA, 2010). Grayson (1997) also cautions that transfers should not be seen as failure on the part of the student or the programme. In this study we include information on the success of students transferring to other programmes such as commerce, humanities, law and education.

Another measure of success is used by Grayson (1997), reporting on the Science Foundation Programme at the (then) University of Natal. This measure of success is based mostly on qualitative factors, sourced through interviews and questionnaires with students, including changes in attitude to learning and learning behaviour, development of practical and cognitive skills, transfer of learning between different contexts, development of academic communication skills, self-awareness and other life skills. In a later report, Grayson (2010) compares the performance of ENGAGE engineering students at the University of Pretoria with that of mainstream engineering students in the subjects that they do together each semester as well as with regard to the percentage of total credits that they passed.

\section{Science Access at the University of Pretoria}

Up to 2008, the science faculty at the University of Pretoria (UP) presented three AD programmes: a BSc extended year programme, the UP Foundation Year Programme and a BSc (four-year) at the Mamelodi campus (formerly part of the Vista University). In 2008 these programmes were consolidated into a single BSc four-year programme, abbreviated to BFYP (Smith, 2007). Changes in government funding policy provided the impetus for this consolidation (Department of Education, 2006; Grayson, 2010), which was further supported by research results confirming the unnecessary duplication of efforts for groups with similar needs (Potgieter, Davidowitz \& Mathabatha, 2008). The replacement programme had four streams, Agriculture and Biology, Physical Science, Mathematical Science and Veterinary Biology (which was discontinued in 2010 because of changes in the veterinary programme). The new programme was introduced with the aim 'to increase the number of graduates in the science and science-based faculties and, following national policy, in particular graduates whose prior learning has been adversely affected by educational and/or social inequalities' (Grayson, 2010). The programme includes an additional year of study that enhances students' basic knowledge and skills before progressing onto more specialist studies in the later years of the programme. It provides dedicated support to students who need assistance to bridge the gap between school and university.

The programme is formally situated within the Faculty of Natural and Agricultural Sciences. A large percentage of students admitted are from previously disadvantaged groups. Selection to BFYP is 
based on Grade 12 results combined with the results of an admissions test. For the 2008 intake of students the so-called AARP tests (Yeld \& Haeck, 2007), developed at the Centre for Higher Education Development, University of Cape Town, were used for selection. The AARP tests have subsequently been replaced by the National Benchmark Tests.

The programme has two phases. During the first phase, which lasts 18 months (three semesters), students receive intensive academic development, psychological support and career guidance for further studies. The academic content is delivered at a slower pace than the normal programmes so that students have more time to engage with the subject content and develop a thorough understanding of the material. During the three semesters of phase 1 the pace increases gradually. By the time students have completed the first phase they should be able to work at the normal speed required of university students. They then continue their studies in the second phase where they join students in the normal three-year mainstream degree programme in their fourth semester, which would be the second semester for the mainstream students. Courses in the programme bear credit. All students do courses in mathematics, physics, chemistry, biology and language and study skills in the first semester. In the second semester differentiation occurs depending on the stream that students are enrolled in. Since the majority of AD students are second-language English speakers, courses in language and study skills are included in the first two semesters, addressing a well-recognised barrier to learning that most of these students are facing (Grayson, 1996). At the end of each semester, students have to meet certain levels of academic performance in order to continue in the programme. Career guidance and counselling provide support to help students adjust to the demands of tertiary studies.

BFYP has some characteristic features. All teaching activities are done by the discipline departments rather than within the programme itself. In addition to small tutorial classes where students receive individual attention, they also attend lectures in large groups where the teaching style is more formal in order to prepare students for the second phase of the programme.

The first two semesters of the programme are presented at Mamelodi Campus of the university and students then transfer to the Hatfield Campus after successful completion of the first year. After successfully completing the first 18 months of the programme, students obtain credit for the first semester of a three-year mainstream degree.

The strategy of BFYP to increase the number of black students in science programmes is viewed as one of the university's priorities. The national Department of Higher Education and Training has shown its support by subsidising the programme. Financial assistance ranging from full scholarships to partial bursaries is available for the first year of study (two semesters) to increase the number of black students in the programme.

\section{Research Focus}

In this article, five quantitative criteria were used to measure the success of a particular $A D$ programme:

- retention in the programme;

- completion rate, in terms of both eventual completion rate and completion rate in minimum time;

- number of students successfully migrating to other faculties, specifically science-related faculties;

- programme performance statistics compared with other universities;

- enrolment numbers for postgraduate studies.

The objective of the study is to evaluate the success of the UP programme using these quantitative criteria. As discussed earlier, retention and throughput are commonly used for evaluation of programmes. In view of the somewhat deficient career guidance provided by secondary schools, however, success can also be defined in terms of the extent to which access to coveted study programmes and professions becomes possible that would otherwise have been denied to students from disadvantaged backgrounds. Indirect evidence for this criterion may consist of the extent of transfer between programmes and faculties and drop-out in later years. 
In a separate article we conducted a qualitative study in which we sourced opinions from students on their experience of the programme (Potgieter, Harding, Kritzinger, Somo \& Engelbrecht, 2014).

\section{Research Design}

Student data for the 2008 student intake ( $N=346$ students) were obtained from the Bureau for Institutional Research and Academic Planning at the University of Pretoria. Performance data for the eight semesters from 2008 to 2011 were analysed for retention, throughput and transfer between faculties. The faculty student advisor conducted interviews with students to obtain reasons for dropping out in the first year.

\section{Results and Discussion}

\section{Retention and Throughput}

Enrolment in the different streams of the BSc Four-Year Programme and attrition rates during the first year are summarised in Table 2.

Ideally, students should be able to make an informed decision about a future career in a scientific field within the first year of BFYP, seeing that counselling and career guidance services are readily available at that stage. Table 2 shows that, after the first year, 95 (346 minus 251) students did not return to register in January 2009 , which reflects an attrition rate of $27 \%$ in the first year of BFYP.

By the end of the fourth year a total of 136 students had discontinued their studies on their own accord or were excluded by the institution. This means that $70 \%$ (95 of 136) of students whose studies were terminated were lost during or at the end of the first year of the programme. While attrition is normal and to be expected (these students are under-prepared), it is difficult to define a level at which the attrition rate is 'acceptable'. Given the staffing investment and extensive support provided during the first year of BFYP, the university has high expectations of performance outcomes of students.

While high attrition during the first year is the pattern at tertiary institutions in South Africa (Council on Higher Education, 2013), it is still a reason for concern that warrants further investigation. Personal

Table 2: Destination of students after one year in BFYP

\begin{tabular}{|c|c|c|c|c|c|c|}
\hline & & $\begin{array}{c}\text { Mathematical } \\
\text { sciences }\end{array}$ & $\begin{array}{l}\text { Physical } \\
\text { sciences }\end{array}$ & $\begin{array}{c}\text { Biological and } \\
\text { agricultural } \\
\text { sciences }\end{array}$ & $\begin{array}{l}\text { Veterinary } \\
\text { sciences }\end{array}$ & Total \\
\hline \multirow{11}{*}{$\begin{array}{l}\text { Students } \\
\text { enrolled per } \\
\text { faculty in } \\
\text { January } 2009\end{array}$} & $\begin{array}{l}\text { Registered } \\
\text { January } 2008\end{array}$ & 28 & 185 & 105 & 28 & 346 \\
\hline & $\begin{array}{l}\text { Registered } \\
\text { January } 2009\end{array}$ & 24 & 133 & 78 & 16 & 251 \\
\hline & Attrition (rate \%) & $4(14 \%)$ & $52(28 \%)$ & $27(26 \%)$ & $12(43 \%)$ & $95(27 \%)$ \\
\hline & Science faculty & 24 & 95 & 37 & 13 & 169 \\
\hline & $\begin{array}{l}\text { Selected for health } \\
\text { sciences }\end{array}$ & - & 1 & 13 & - & 14 \\
\hline & $\begin{array}{l}\text { Selected for } \\
\text { engineering }\end{array}$ & - & 23 & - & - & 23 \\
\hline & Commerce & - & 7 & 7 & 2 & 16 \\
\hline & Humanities & - & 4 & 18 & 1 & 23 \\
\hline & Education & - & 1 & 2 & - & 3 \\
\hline & Law & - & 2 & 1 & - & 3 \\
\hline & $\begin{array}{l}\text { Total in faculties } \\
\text { other than science }\end{array}$ & 0 & 38 & 41 & 3 & 82 \\
\hline
\end{tabular}


interviews conducted with students by the faculty student advisor (Potgieter et al., 2014) indicate the following main reasons for students dropping out of the programme in the first year:

- students with poor study skills but with a false perception of competence seeking help too late;

- lack of finances for food, books and rent before bursaries are paid out;

- wrong career choices;

- accommodation away from campus and exhaustion due to long travelling times; students are sometimes exposed to traumatic events when travelling;

- excessive participation in first-year orientation events and professional sports;

- continued feeling of failure for not gaining access to mainstream programmes;

- lack of social or family support and family crises that must be dealt with;

- health and psychological conditions, including depression and poor eyesight, impacting on class attendance, sometimes resulting in hospitalisation;

- wrongly seeing this first year as a 'gap-year' to get access to mainstream and then not committing enough time to study;

- lack of motivation-sometimes doing the degree for the sake of a parent;

- lack of academic knowledge of the basics of language, computer skills and mostly mathematics and chemistry.

These reasons for dropout are quite similar to those found by Lubben, Davidowitz, Buffler, Allie and Scott (2010) for academic development students at the University of Cape Town.

Table 2 also shows that 82 students (24\%), that is, almost a quarter of the students, transferred to other faculties after one year. Of these students $45 \%$ (37 of 82 ) were selected for science-related programmes for which BFYP is acting as seeding ground, that is, engineering and the built environment (23 students, $28 \%$ ) and health sciences (14 students, 17\%). In addition, 16 students (18\%) transferred to programmes offered by the commerce faculty, 23 students $(28 \%)$ transferred to the faculty of humanities and three students (4\%) each to education and law programmes. The highest transfer rate comes from the biological sciences $(39 \%, 41$ of 105$)$ to the related field of health sciences $(32 \%, 13$ of 41$)$, and somewhat unexpectedly, mostly to humanities $(44 \%, 18$ of 41$)$. Transfer to faculties other than health sciences and engineering represents a loss in terms of the core purpose and design of BFYP, but can also be viewed positively in the light of students taking informed career decisions when given the opportunity to explore their interests and aptitudes.

Table 2 also provides information regarding the attrition rates from different streams during the first year. The smallest attrition rate $(14 \%)$ is in mathematical sciences, an unexpected result as mathematics is often perceived as a difficult field, and there are no transfers from this stream to other faculties. Possibly these students would have entered BFYP with actuarial or financial mathematics in mind and were unable to transfer to engineering unless they had chosen physics and chemistry as electives in the second semester of the first year. At the other extreme, almost half of the students enrolled in the veterinary science stream discontinued their studies or did not return for the second year (12 of 28 , $43 \%$ ), which may suggest that career choices are often based on unrealistic expectations.

Progression through the four-year period of 2008-2011 is reported in Table 3.

Table 3: Progression through undergraduate studies during the period 2008-2011

\begin{tabular}{llc}
\hline Academic year & Students enrolled & Graduated \\
\hline 2008 & 346 & \\
2009 & 251 & \\
2010 & 226 & 1 \\
2011 & 212 & 53 \\
2012 & 144 undergraduate & \\
& 30 postgraduate & \\
\hline
\end{tabular}




\section{Year 2}

In Year 2 there were 25 students who discontinued their studies or were excluded. The only transfer between faculties that occurred in the middle of the second year was a single student to engineering and one to commerce. However, at the end of the second year further migration to other faculties occurred: engineering (three), health sciences (one), commerce (nine) and theology (one). From Year 2 to Year 3 there was a total attrition rate of 10\% (25 students), markedly lower than in Year 1.

\section{Year 3}

Fourteen students discontinued their studies during the year, eight of whom were from the Faculty of Natural and Agricultural Sciences (NAS). However, five students who did not complete their first year successfully returned to tertiary studies in Year 3 and enrolled for direct entry to NAS (one), commerce (one) and education (three). At the end of the third year 212 students were still academically active and continued with their studies in Year 4. From Year 3 to Year 4 there was an attrition rate of 6\% (14 students), continuing the downward trend set in the previous two years.

\section{Year 4}

The distribution of student enrolment by faculty during Year 4 was $60 \%$ in NAS (128 of 212), 12\% in engineering, $11 \%$ in commerce, $7 \%$ each in health sciences and humanities, and roughly $1 \%$ each in education, law and theology. The majority of students who transferred to commerce selected programmes with a strong numerical focus, such as econometrics, statistics, financial management and auditing. The end of the fourth year was the first opportunity for students who started BFYP in 2008 to graduate in degree programmes with a minimum duration of three years. Statistics regarding this year are presented in Table 4, differentiated according to 2008 enrolment in a specific stream.

Table 4 shows that $61 \%$ (212 of 346) of the cohort initially admitted to BFYP enrolled at the start of the 2011 academic year with 53 graduating at the end of the year. The group of 53 who completed the programme successfully in the minimum time at the end of 2011 represents $15 \%$ of the original cohort and $25 \%$ of those that were enrolled at the start of 2011 . The degrees awarded were in science and agriculture (30), the humanities (12), construction management (four), economics (three), radiography (two), architecture (one) and computer science (one). The percentage of students who successfully completed a degree should increase with time because there are still 144 students of the initial cohort in the system registered for undergraduate studies in 2012. The percentage of students to obtain a first degree could in time rise to a maximum of $57 \%(53+144$ of 346$)$. Similarly, the rate of completion in minimum time may increase to a maximum of $26 \%$ of the original cohort as some of the students enrolled in non-NAS programmes with a duration of 4 years or more to complete their studies $(53+36$ of 346$)$. These programmes are in health sciences, engineering, agriculture and education.

Table 4: Student success rates per BFYP stream

\begin{tabular}{llccc}
\hline & $\begin{array}{l}\text { Enrolment } \\
\text { BFYP stream }\end{array}$ & $\begin{array}{c}\text { Still registered } \\
\text { in 2011 }\end{array}$ & $\begin{array}{c}\text { Students enrolled in non-NAS } \\
\text { programmes with duration 4 years } \\
\text { or more }\end{array}$ & $\begin{array}{c}\text { Students } \\
\text { graduated end of } \\
2011^{\text {a }}\end{array}$ \\
\hline $\begin{array}{l}\text { Mathematical } \\
\text { Sciences }\end{array}$ & 28 & $21(72 \%)$ & 0 & $1(4 \%)$ \\
$\begin{array}{l}\text { Physical sciences } \\
\text { Biological and }\end{array}$ & 185 & $112(62 \%)$ & 16 & $23(12 \%)$ \\
$\begin{array}{l}\text { agricultural sciences } \\
\text { Veterinary sciences }\end{array}$ & 105 & $66(63 \%)$ & 17 & $25(24 \%)$ \\
Total & 28 & $13(43 \%)$ & 3 & $4(14 \%)$ \\
\hline
\end{tabular}

a Percentage of student graduates based on 2008 enrolment in the specific stream. These students enrolled in programmes with a minimum duration of 4 years for students in the BFYP. 
The programmes that were the most challenging for these students, resulting in exclusion after four years, were actuarial and financial mathematics, and mathematical statistics, drawing students from both the BFYP mathematical sciences and physical sciences streams. The requirements for admission to BFYP mathematical sciences have always been more stringent than for the other three streams, but have since been raised further in response to this result.

\section{Year 5}

At the start of 2012, the fifth academic year for the 2008 cohort of BFYP students, a total of 144 students registered for undergraduate programmes and 30 for advanced degree (Honours) programmes in various branches of science (18), architecture and construction (five), humanities (three), commerce (two) and education (two).

\section{Measuring Success of the Programme}

The data presented above enables us to measure the success of the BFYP according to the five identified success indicators.

\section{Retention}

A total of 155 students discontinued their studies of their own accord or after exclusion during four years. The majority of these students (95 of 155) left during the first year, but six students returned after a period of absence. The attrition rate over the first year of $27 \%$ is high, but it is on a par with attrition rates reported at other South African universities such as UKZN (Downs, 2010), and can be attributed to a number of factors. Access to BFYP on grounds of performance in the admissions tests and Grade 12 results offers fair criteria but the selection process is by no means perfect. A total of 346 students were admitted to the programme. The selection of 20 students with very weak prior mathematics performance was probably unjustified, taking into account the finding by Potgieter, Ackermann and Fletcher (2010) that Grade 12 performance in mathematics is the strongest predictor of success in first-year science courses. Since there are no perfectly reliable selection tests available for the identification of academic potential, we consider this an acceptable margin of error in student selection. Once in the system these students need to adapt to becoming independent, self-regulated learners, similar to what is expected of mainstream students, but simultaneously to overcome their under-preparedness -in fact, the objective of the programme is to prepare them for this. It is to be expected that not all of these students will be successful and an important aspect of the programme should be that there are early indicators of non-success, which all parties involved should be alerted to. The somewhat high attrition rate of the first year is worrying and yet the fact that this happened early on in the programme contributes to some extent to the success of the programme in that some of these students realised early that a degree in science was not for them-they were given the opportunity but chose an early exit. Not all students' decisions to discontinue can be attributed to the programme. Some decisions constitute a conscious and judicious decision on the students' part.

The attrition rate decreased considerably over the four-year period, but it remains a matter of concern that almost a third of the attrition occurred later, possibly because students did not make a successful transition to the mainstream or did not cope with the demands of the programmes that they had chosen. The findings from the interviews with students by the faculty student advisor in later years (Potgieter et al., 2014) show that ability is not always the main reason for discontinuing studies, but rather it is affected by their time management, the availability of time (when travelling far), availability of resources (e.g. textbooks, food), psychological and/or physical health reasons, lack of funds to continue or simply no interest in the degree they are doing.

\section{Completion Rates}

It is anticipated that the completion rate of this cohort of students will rise to above $50 \%$ in time, with a ceiling of $57 \%$ (many of these students are still studying). Ideally one would have liked this percentage to be higher. However, BFYP offered access to coveted professional careers to almost 200 students 
who would not have had access otherwise. Completing the degree that a student initially enrolled for in minimum time is a certainly one measure of success. The completion rate of $15 \%$ at the end of 2011 may seem low at first glance but it should be remembered that this is a preliminary result since a further 36 students are enrolled in programmes with longer duration, which could boost this number. The graduation rate for 2008 mainstream students completing three-year programmes in NAS in minimum time was $32 \%$. While these numbers cannot be compared directly, it does indicate that mainstream science programmes at UP are also characterised by a fairly low throughput rate. Students accepted for BFYP have to overcome a number of obstacles, including background, confidence and other personal issues during their studies. They are accepted in BFYP exactly because they are not on a par with mainstream students at the beginning of their studies.

\begin{abstract}
Migration
BFYP was designed to recruit more students into the scarce skills field of science and mathematics. Roughly a quarter of the students migrated to other faculties in or directly following the first year and therefore the potential final completion rate of $57 \%$ quoted above would decrease considerably if one only considered gains to science alone. However, most of these students migrated to sciencerelated programmes, especially to the health sciences and engineering sciences, and for this reason these students are not considered to be lost to science. Most of these transfers occurred during or at the end of the first year. However, almost $80 \%$ of the students still active in the fourth year were enrolled in natural and agricultural sciences, engineering or health sciences, which attests to the contribution of the programme to achieving its core purpose.
\end{abstract}

\title{
Comparison with other Institutions
}

The completion rate of $15 \%$ in minimum time is certainly low, but should the potential completion rate of $57 \%$ be realised, it would be comparable to that of WITS and UKZN, which quoted figures of just under 50 and $63 \%$, respectively (HELTASA, 2010).

\section{Postgraduate Entries}

Perhaps the most significant indicator of the contribution of BFYP in terms of participation in tertiary education in a research-intensive university is the fact that more than half of the students who graduated in 2011 enrolled for postgraduate studies in 2012 (30 of 53, 57\%). This is a major achievement, especially when considering that 23 of these students are enrolled in science-related programmes and that none of them would have had access to any science degree programmes at UP in the absence of the BFYP programme. Not only did they complete their undergraduate studies successfully, but they performed well enough to be admitted to postgraduate programmes where they will be inducted into the culture of research.

\section{Conclusions}

The study reported on in this paper set out to evaluate the success of BFYP, using the criteria identified: retention in the programme, completion rate, the number of students successfully migrating to other faculties, programme performance statistics compared with other universities and enrolment numbers for postgraduate studies. The programme can be considered as moderately successful with regard to retention and completion rate in comparison with other similar programmes at other universities. Regarding graduate enrolment and the science-based migration to other faculties, the data seem to indicate that the programme is succeeding.

Although this study seems to indicate that the programme is successful according to the criteria we used for measurement, we realise that the results could be biased since we used mostly quantitative data in the study. For triangulation purposes a qualitative study was conducted (Potgieter et al., 2014). Judging by students' opinions of the programme, there does not appear to be any inherent problematic issues in the programme while it is possible to build on the current strengths. 
In the absence of better models for the prediction of university success, this programme serves a secondary purpose of guiding students at an early stage in gauging their prospects of success, and their interest, in science-related programmes at university.

The programme serves an important purpose in that many students for whom a study programme in science would not have been possible are succeeding in their studies in science.

\section{Acknowledgements}

The authors wish to acknowledge the dedicated work of Sarah Ramage, Paidamwoyo Mangondo and Sherilee Pillay in processing the data for this project.

\section{References}

Boughey, C. (2007). Marrying equity and efficiency: The need for third generation academic development. Perspectives in Education, 25(3), 1-11.

Boughey, C. (2010). Understanding teaching and learning at foundation level: A 'critical' imperative? In Beyond the university gates: Provision of extended curriculum programmes in South Africa. Proceedings of the January 2009 Rhodes University Foundation Seminar. Rhodes University, Grahamstown.

Campbell, G., \& Prew, M. (2014). Behind the matric results: The story of maths and science. Mail \& Gaurdian, 7 April 2014. Retrieved July 17, 2014 from http://mg.co.za/article/2014-01-07-behind-the-matric-results-the-story-ofmaths-and-science

Case, J., Marshall, D., \& Grayson, D. (2013). Mind the gap: Science and engineering education at the secondarytertiary interface. South African Journal of Science, 109(7/8), 1-5.

Council on Higher Education (2013, August). A proposal for undergraduate curriculum reform in South Africa: The case for a flexible curriculum structure. Pretoria: Council on Higher Education.

Department of Basic Education (2014). NSC 2013 Examination Results. Pretoria: Department of Basic Education.

Department of Education (2006). Funding for foundational provision in formally approved programmes: $2007 / 08$ to 2009/10. Pretoria: Department of Education.

Dhunpath, R., \& Vithal, R. (Eds) (2013). Alternative access to higher education: Underprepared students or underprepared institutions? Cape Town: Pearson.

Downs, C.T. (2010). Increasing equity and compensating historically academically disadvantaged students at a tertiary level: Benefits of a Science Foundation Programme as a way of access. Teaching in Higher Education, 15, 97-107.

Grayson, D. (1996). A holistic approach to preparing disadvantaged students to succeed in tertiary science studies. Part I. Design of the Science Foundation Programme (SFP). International Journal of Science Education, 18(8), 993-1013.

Grayson, D. (1997). A holistic approach to preparing disadvantaged students to succeed in tertiary science studies. Part II. Outcomes of the science foundation programme. International Journal of Science Education, 19(1), 107-123.

Grayson, D. (2010). Design of the engineering augmented degree programme. Retrieved April 2012 from http:// www.assaf.org.za/wp-content/uploads/2010/10/Grayson-Engineering-Augmented-Degree.pdf

HELTASA (2010). Success stories in foundation/extended programmes. Retrieved April 23, 2012 from http://www0. sun.ac.za/heltasa/file.php/1/Foundation/Final_Book.pdf

Inyathelo (2014). Student access and success: Issues and interventions in South African universities. Retrieved July 28, 2014 from http://www.inyathelo.org.za/images/docs/report_summary_student_access_\%20success_ sauniversities2014.pdf

Kioko, J. (2010). Foundation provision in South African Higher Education: A social justice perspective, in Beyond the university gates: Provision of extended curriculum programmes in South Africa. Proceedings of the January 2009 Rhodes University Foundation Seminar. Rhodes University, Grahamstown.

Kirby, N., \& Dempster, E. (2011). The (re)construction of a philosophical and pedagogical position for the Foundation Programme at UKZN with particular reference to the Biology module. South African Journal of Higher Education, 25(6), 1103-1124.

Lubben, F., Davidowitz, B., Buffler, A., Allie, S., \& Scott, I. (2010). Factors influencing access students' persistence in an undergraduate science programme: A South African case study. International Journal of Educational Development, 30(4), 351-368. 
Potgieter, M., Davidowitz, B., \& Mathabatha, S. (2008). Preparedness for tertiary chemistry: Issues of placement and performance of academic development programmes. South African Journal of Higher Education, 22(4), 861-876.

Potgieter, M., Ackermann, M., \& Fletcher, L. (2010). Inaccuracy of self-evaluation as additional variable for prediction of students at risk of failing first-year chemistry. Chemical Research Education Research and Practice, 11, 17-24.

Potgieter, M., Harding, A., Kritzinger, Q., Somo, C., \& Engelbrecht, J. (2014). Reflections of science students on their experience of an academic development programme in South Africa. South African Journal of Higher Education (in press).

Scott, I., Yeld, N., \& Hendry, J. (2007). Higher Education Monitor: A Case for Improving Teaching and Learning in South African Higher Education. Pretoria: Council for Higher Education.

Smith, U. (2007, October). Business plan for the BSc: Four year programme to be introduced by the Faculty of Natural and Agricultural Science. University of Pretoria.

SUNY (2012). Guide for the evaluation of undergraduate academic programs. State University of New York. Retrieved January 20, 2014 from www.suny.edu

Van der Flier, H., Thijs, G., \& Zaaiman, H. (2003). Selecting students for a South African mathematics and science foundation programme: The effectiveness and fairness of school-leaving examinations and aptitude tests. International Journal of Educational Development, 23, 399-409.

White, C.J. (2011). On the evaluation of teaching and learning in higher education: A multicultural inquiry. Assessment \& Evaluation in Higher Education, 36(6), 643-656.

Yeld, N., \& Haeck, W. (2007) Educational Histories and Academic Potential: Can tests deliver?. Assessment and Evaluation in Higher Education, 22, 5-16. 